\title{
MODEL PENDAYAGUNAAN ENERGI GEOTERMAL ENTALPI RENDAH (DIRECT-USE) DI JAWA BARAT
}

\author{
CUKUP MULYANA*, NUMAN LUTHFI, ASWAD HI SAAD \\ Departemen Fisika Fakultas MIPA Universitas Padjadjaran, \\ Jl. Raya Bandung-Sumedang Km 21, Jatinangor 45363 \\ *email :c.mulyana55@yahoo.com
}

\begin{abstract}
Abstrak. Jawa Barat memiliki potensi energi geotermal dalam jumlah yang besar. Akan tetapi pemanfaatannya terbatas untuk sumber geotermal dengan entalpi tinggi, yaitu sebagai penghasil tenaga listrik. Sementara itu pemanfaatan potensi energi geotermal dengan entalpi rendah masih belum dimanfaatkan dengan baik. Jika energi geotermal terbuang ini dapat diberdayakan, maka energi tersebut diharapkan akan meningkatkan pembangun perekonomian dan kesejahteraan masyarakat di wilayah Jawa Barat. Dalam penelitian ini dilakukan pendataan sumber energi geotermal berentalpi rendah yang berada di Jawa Barat, yang kemudian hasil pendataan potensi pertanian, perkebunan dan industri tersebut dikorelasikan dengan energi geotermal berentalpi rendah yang telah diperoleh sebelumnya. Setelah itu, dibuat peta potensi geotermal dan pemanfaatannya di setiap titik di propinsi Jawa Barat. Hasil pemetaan tersebut digunakan untuk membuat model pendayagunaan entalpi rendah di Jawa Barat yang mengintegrasi peran akademisi, peneliti, masyarakat, pemerintah daerah, pemerintah pusat, dan pelaku usaha sebagai pemilik modal dalam sebuah networking yang sinergis. Pengaplikasian model pendayagunaan energi geotermal ini menjanjikan banyak keuntungan yaitu: meningkatkan ketahanan melalui pemanfaatan energi terbarukan, keuntungan kelestarian lingkungan, dan keuntungan atas sosial, politik dan ekonomi masyarakat di Jawa Barat.
\end{abstract}

Kata kunci : energi geotermal, entalpi rendah, peta potensi, model pendayagunaan, ketahanan energi

\begin{abstract}
West Java has a great number of geothermal energy's potency. However, the utilization is only limited on geothermal resources with high enthalpy which has been being used only for generating electrical energy. Meanwhile geothermal resources with low entalphy have not been utilized well yet. If this wasted energy can be empowered, it is expected to increase the economic development and social welfare in West Java. In this research, we have collected the data of geothermal energy resources in West Java, furthermore those datas of agriculture, plantation and industry potency are correlated with low entalphy resources that have been obtained before. After that, we created a mapping of geothermal potency and its utilization in West Java province. The results of mapping is used as a model of utilizing geothermal energy in West Java which integrates the role of academics, researcher, local society, local government, central government, and businessperson in a synergistic networking. Applying this model gives many benefits, such as improving energy security with its sustainability, preserving the environment, and increasing economic, social, and political resiliences in local society in West Java.
\end{abstract}

Keywords : geothermal energy, low entalphy, potency map, utilization model, energy security

\section{Pendahuluan}

Sumber energi geotermal untuk kepentingan non-listrik dikenal sebagai sumber energi geotermal yang digunakan secara langsung "direct-use". Sumbernya 
berasal dari sistem hidrotermal yang berada di dalam bumi sebagai akibat adanya aktivitas vulkanis dan tektonis. Umumnya dijumpai dalam fasa air dan uap panas dengan temperatur rendah. Berdasarkan DOE National Laboratory (2004), kategori temperatur sumber energi geotermal direct-use adalah berentalpi rendah hingga menengah dengan kisaran temperatur pada $20^{\circ} \mathrm{C}-150^{\circ} \mathrm{C}$ atau $68^{\circ} \mathrm{F}-302^{\circ} \mathrm{F}$ [1].

Jawa Barat adalah provinsi di Indonesia dengan potensi energi geotermal dalam jumlah besar. Akan tetapi pemanfaatannya masih terbatas pada pembangkit energi listrik. Di sisi lain, Jawa Barat adalah salah satu pusat industri kreatif besar nasional, yang juga memiliki komoditas pertanian dan perkebunan yang melimpah. Dilatarbelakangi oleh hal tersebut, potensi sumber energi geotermal dengan entalpi rendah dapat digunakan untuk mengolah berbagai komoditas yang pula turut dapat meningkatkan roda perekonomian dan pembangunan di Jawa Barat.

Tujuan dari penelitian ini pertama adalah memetakan potensi energi geotermal berentalpi rendah untuk digunakan dalam memproses komoditas lokal yang berada di sekitar sumber energi tersebut di wilayah Jawa Barat. Tujuan berikutnya yaitu membuat model pemberdayaan energi geotermal berentalpi rendah dengan mensinergikan berbagai kalangan, seperti akademisi, peneliti, masyarakat, pemerintah, pemilik modal di provinsi Jawa Barat. Jika model ini dapat direalisasikan, maka manfaatnya akan meningkatkan ketahan energi dan ekonomi masyarakat lokal Jawa Barat itu sendiri.

\subsection{Perbedaan Direct-Use dan Indirect-Use}

Berdasarkan temperatur fluida, pemanfaatan sumber energi geotermal digolongkan menjadi sumber energi geotermal direct-use dan indirect-use.

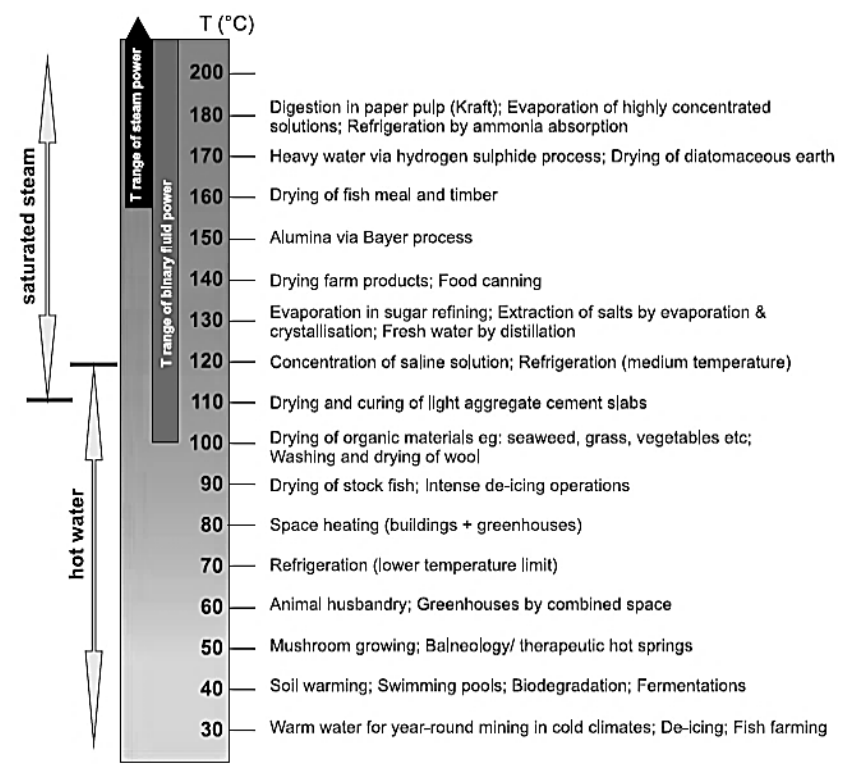

Gambar 1. Penggolongan pemanfaatan sumber energi geotermal golongan direct berdasarkan temperatur dan fase zat (modifikasi Lindal (1973) [2]

Menurut Johannesson dan Chatenay (2014), penggunaan langsung sumber geotermal (direct-use) adalah penggunaan energi panas atau fluida geotermal dari sumbernya tanpa terlebih dahulu diubah menjadi energi lain, misalnya energi 
listrik [3]. Maka penggunaan tidak langsung sumber geotermal indirect-use adalah penggunaan energi panas dari sumber geotermal dengan terlebih dahulu mengonversinya ke bentuk energi lain seperti energi listrik. Wood (1973) menyatakan penggunaan energi geotermal tidak langsung (indirect-use) adalah pemanfaatan uap mentah melalui heat exchanger yang digunakan untuk mendidihkan ulang kondesat primer menjadi uap murni dengan tekanan rendah [7].

Berdasarkan rentang temperatur sumber energi termal direct-use adalah $30^{\circ} \mathrm{C}$ $180^{\circ} \mathrm{C}$. Berdasarkan fasenya wujud air panas diperoleh pada rentang temperatur $30^{\circ} \mathrm{C}-110^{\circ} \mathrm{C}$, sedangkan pada rentang temperatur $110^{\circ} \mathrm{C}-180^{\circ} \mathrm{C}$ berwujud uap. Penggolongan penggunaan direct-use untuk berbagai karakteristik terlihat pada Gambar 1, Lindal(1973) [4].

\subsection{Sumber Energi Geotermal Direct-Use}

Berdasarkan sumbernya, energi geotermal direct-use dikelompokan menjadi 3 jenis, yaitu [9] :

- Manifestasi gunung berapi, dalam bentuk sumber air panas dan uap panas;

- Panas terbuang pembangkit geotermal, dalam bentuk brine dan kondensat;

- Akuifer panas / Non-Gunung Berapi, dalam bnetuk sedimentary basin;

\subsection{Aplikasi Energi Geotermal Direct-Use}

Menurut Johannesson dan Chatenay (2014), pemanfaatan sumber geotermal golongan direct-use untuk pembangkit listrik dry steam, flash steam dan binery system jarang dilakukan terutama karena alasan ekonomis [3]. Oleh karena itu, fluida geotermal berentalpi rendah akan lebih efisien bila dimanfaatkan secara langsung (lihat Gambar 1).

Berdasarkan data tahun 2010, prosentasi distribusi penggunaan energi geotermal golongan direct-use di seluruh dunia ditunjukan dalam satuan total energi seperti pada Gambar 2. Secara umum, aplikasi yang terpasang digunakan sebagai fluida pada pompa panas, pemanas ruangan, pendingin ruangan, pengontrol temperatur rumah kaca - pemanas tanah, penunjang akuakultur, pengering hasil panen pertanian, pemanas dalam proses industri, pencairan salju, dan media pemandian serta kolam renang [5].

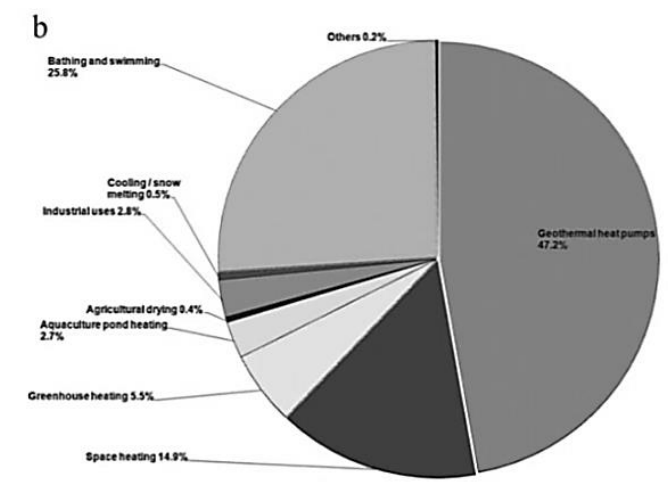

Gambar 2. Aplikasi langsung geotermal dunia tahun 2010, didistribusikan oleh persentase penggunaan total energi [5] 


\subsection{Manfaat Penggunaan Energi Geotermal secara Langsung}

Penggunaan energi geotermal secara langsung banyak memberikan manfaat, baik secara ekonomi, lingkungan, dan dari efisiensi energinya. Manfaatnya adalah sebagai berikut [2] :

- Biaya pemanasan yang rendah dengan mengurangi konsumsi listrik, minyak, dan gas yang digunakan dalam produksi

- Emisi $\mathrm{CO}_{2}$ dan oksida-oksida nitrogen serta sulfur yang rendah dengan mengurangi konsumsi bahan bakar fosil dalam membangkitkan energi listrik;

- Sumber energi yang lebih baik dengan mengurangi konsumsi bahan bakar kualitas tinggi untuk kebutuhan pemanasan rendah;

- Biaya perawatan dan kebutuhan lainnya yang rendah setelah instalasi;

Manfaat tersebut didukung oleh data dan pernyataan U.S Department of Energy, bahwa pemanfaatan sumber geotermal direct-use, baik dalam skala produksi komersil dan non-komersil, memiliki kebutuhan biaya operasi yang lebih murah dibandingkan pemanfaatan sumber energi fosil hingga mencapai sebesar $80 \%$. Pemanfaatan energi geotermal pula lebih ramah lingkungan dengan pengemisian polutan yang lebih rendah dibandingkan pembakaran bahan bakar fosil [1].

\section{Metode Penelitian}

Metode yang digunakan dalam penelitian ini adalah observasi literatur dan pengumpulan data di lapangan. Data-data literatur diperoleh dari berbagai sumber kemudian disusun dan dikelompokan untuk pembuatan peta potensi yang dikorelasikan dengan mata pencaharian lokal dan sebagai dasar pembuatan model pendayagunaan energi geotermal berentalpi rendah di Jawa Barat.

1. Kelompok data pertama berisikan data penunjang berupa potensi-potensi sumber energi geotermal dan mata pencaharian (heat user). Data sumber energi geotermal diperoleh berdasarkan lokasi sumber di sekitar provinsi Jawa Barat dan nilai temperatur sumber di reservoir serta permukaan, sebagai bentuk hasil survey secara geologi dan geokimia, sedangkan data mata pencaharian diperoleh berdasarkan jumlah konsentrasi pelaku usaha pada suatu lokasi di provinsi Jawa Barat. Selanjutnya data tersebut diolah menjadi sebuah peta potensi yang mencocokan wilayah sumber energi geotermal dan mata pencaharian lokal sehingga dihasilkan peta pemanfaatan energi geotermal di Jawa Barat.

2. Kelompok data kedua berisikan inventarisasi pihak-pihak yang terlibat dalam model pemberdayagunaan. Terdapat 5 kerangka aktivitas utama, yaitu observasi potensi (energi geotermal entalpi rendah, mata pencaharian lokal, dan industri), pre-processing, mekanisme pemanfaatan, poduksi produk, dan konsumen. Kemudian hasil inventarisasi pihak-pihak yang terlibat dipetakan pada masing-masing kerangka aktivitas utama dengan bentuk kegiatan tersendiri di setiap aktivitas utama. Sehingga pada akhir penelitian akan diperoleh model yang terintegrasi.

Sehingga pada penelitian ini bentuk akhir yang akan diperoleh berupa review singkat potensi geotermal dan aplikasi serta solusi pengembangannya di masyarakat. 


\section{Data Literatur : Potensi Geotermal dan Mata Pencaharian}

\subsection{Potensi Geotermal Wilayah Indonesia dan Jawa Barat}

Menurut BPPT (2010), Indonesia merupakan negara dengan sistem hidrotermal untuk sumber geotermal terbesar di dunia dengan potensi lebih dari 17.000 MW. Akan tetapi, pemanfaatan energi geotermal di Indonesia saat ini hanya sebesar $1.179 \mathrm{MW}$ atau $4 \%$ dari potensi yang ada. Data ini terbatas untuk membangkitkan tenaga listrik saja (indirect-use) [6].

Berdasarkan data statistik dunia Lund, J. W, et al (2010) menunjukan bahwa rasio kapasitas geotermal non-listrik (direct-use) di Indonesia masih sangat kecil dari sarana maksimum yang telah terpasang. Berdasarkan kapasitas termalnya, rasio kapasitas tersebut setara dengan 2,3MWt. Pemanfaatan energi geotermal secara langsung ini, setiap tahun dapat mencapai sebesar 42,6TJ/yr dalam bentuk kerja atau sebesar 11,8GWh/yr dalam energi listrik (lihat Tabel 1) [5].

Tabel 1. Rangkuman data statistik direct-use untuk dunia tahun 2010 [5]

\begin{tabular}{|c|c|c|c|c|}
\hline \multicolumn{5}{|c|}{ ENERG GEOTERMAL DIRECT-LSE NEGARA-NEGARA DUNIA } \\
\hline Negara & $\begin{array}{c}\text { Kapasit as Termal } \\
\text { (MWt) }\end{array}$ & $\begin{array}{c}\text { Pemanfaatan Tahunan } \\
\text { (TJ/yr) }\end{array}$ & $\begin{array}{c}\text { Pemanfatan Tahunan } \\
\text { (GTh/yr) }\end{array}$ & $\begin{array}{c}\text { Faktor } \\
\text { Kapasitas }\end{array}$ \\
\hline Australia & 33,33 & 235,1 & 65,3 & 0,22 \\
\hline China & $8.898,0$ & 75348,3 & $20,931.8$ & 0,27 \\
\hline-- & -- & - & - & - \\
\hline India & 265,0 & 2545,0 & 707,0 & 0,30 \\
\hline Indonesia & 2,3 & 426 & 11.8 & 0,59 \\
\hline-- & -- & - & - & - \\
\hline Jepang & 2099,53 & $25,697,94$ & 7.1389 & 0,39 \\
\hline Korea Selatan & 229,3 & $1.954,65$ & 543,0 & 0,27 \\
\hline United Kungóm & 186,62 & 849,74 & 236,1 & 0,14 \\
\hline United Stutes & $12.611,46$ & 56551.8 & $15.710,1$ & 0,14 \\
\hline
\end{tabular}

Potensi geotermal non-listrik atau entalpi rendah di berbagai daerah di Indonesia cukup strategis untuk dimanfaatkan dalam berbagai aktivitas. Dalam hal ini, sumber geotermal Indonesia umumnya ditemukan di daerah pengunungan yang kaya akan daerah kerja perkebunan (termasuk plantasi), perhutanan, pemandian, resorts, dan hal lainnya yang sangat potensial bagi berbagai macam aplikasi direct-use.

Kesinergisan antara ketersediaan sumber energi dan besarnya aktivitas mata pencaharian di daerah saat ini belum gencar diperhatikan oleh berbagai lini bidang di pemerintahan, khususnya di Jawa Barat. Hal ini terlihat pada banyaknya wilayah terbuka untuk sumber energi geotermal entalpi rendah yang belum dimanfaatkan oleh suatu pemegang usaha (lihat Tabel 2 dan 3)(lihat Gambar 3) [7] [9]. 
Tabel 2. Rangkuman data statistik sumber energi geotermal entalpi rendah wujud air panas pada wilayah terbuka untuk provinsi Jawa Barat 2012 [7]

\begin{tabular}{|c|c|c|c|c|c|c|c|c|}
\hline \multirow[b]{3}{*}{ No } & \multicolumn{8}{|c|}{ TITIK POTENSI PANAS BUMI JAWA BARAT (WILAY AH TERBUKA) } \\
\hline & \multirow[b]{2}{*}{$\begin{array}{c}\text { Kota/ } \\
\text { Kabupaten }\end{array}$} & \multirow[b]{2}{*}{ Lokasi } & \multicolumn{6}{|c|}{ STUDIMANIFESTASI AIR PANAS } \\
\hline & & & $\begin{array}{l}\text { Temper atur } \\
\text { Permukaan }\end{array}$ & $\begin{array}{l}\text { Jenis } \\
\text { Survei }\end{array}$ & $\begin{array}{l}\text { Temperatur } \\
\text { Reservoir }\end{array}$ & $\begin{array}{l}\text { Jeuis } \\
\text { Surrei }\end{array}$ & Tipe & $\begin{array}{c}\text { Potential } \\
\text { of } \\
\text { Hydrogen } \\
\text { (pH) }\end{array}$ \\
\hline 1 & \multirow{3}{*}{ Bogor } & Ciseeng & $39,0^{\circ} \mathrm{C}$ & Geolsimia & - & - & - & $7,0-8,0$ \\
\hline 2 & & Buja1-J asinga & $61,5^{\circ} \mathrm{C}$ & Geolsimia & $110,0^{\circ} \mathrm{C}$ & Geolimia & $\begin{array}{c}\text { Bikarbonat- } \\
\text { Norida }\end{array}$ & 6,74 \\
\hline 3 & & $\begin{array}{l}\text { Gunung } \\
\text { Pancar }\end{array}$ & - & - & $85^{\circ} \mathrm{C}-96^{\circ} \mathrm{C}$ & Geolsinia & $\begin{array}{c}\text { Sulfat- } \\
\text { bikarbonat }\end{array}$ & - \\
\hline 4 & \multirow{2}{*}{ Sulabumi } & Selabintana & $37,5^{\circ} \mathrm{C}$ & Geologi & $130,0^{\circ} \mathrm{C}$ & Geolsimia & Bikarbcnat & 5,5 \\
\hline 5 & & Jampang & $60,0^{\circ} \mathrm{C}$ & Geotsimia & $130,0^{\circ} \mathrm{C}$ & Geotsimia & - & 7,2 \\
\hline 6 & Cianjux & $\begin{array}{l}\text { Tanggeung } \\
\text { Cibungry }\end{array}$ & $\begin{array}{l}41,5^{\circ} \mathrm{C}- \\
70,5^{\circ} \mathrm{C}\end{array}$ & Geolsimia & $\begin{array}{l}103,0^{\circ} \mathrm{C}- \\
197,0^{\circ} \mathrm{C}\end{array}$ & Geolimia & $\begin{array}{c}\text { Klorida- } \\
\text { sulfat }\end{array}$ & - \\
\hline 7 & $\begin{array}{c}\text { Bandung } \\
\text { Barat }\end{array}$ & Saguling & $\begin{array}{l}41,5^{\circ} \mathrm{C}- \\
70,5^{\circ} \mathrm{C}\end{array}$ & Geolsinia & $\begin{array}{l}120,0^{\circ} \mathrm{C}- \\
136,0^{\circ} \mathrm{C}\end{array}$ & Geolvimia & $\begin{array}{c}\text { Kiorida- } \\
\text { bikarbonat }\end{array}$ & - \\
\hline 8 & Bandung & Cipacing & $\begin{array}{l}420^{\circ} \mathrm{C}- \\
49,0^{\circ} \mathrm{C}\end{array}$ & Geologi & $160,0^{\circ} \mathrm{C}$ & Geolsimia & $\begin{array}{c}\text { Bikarbonat- } \\
\text { Norida }\end{array}$ & 8,98 \\
\hline 9 & \multirow{2}{*}{ Gant } & Cilayu & - & - & $\begin{array}{l}230,0^{\circ} \mathrm{C}- \\
250,0^{\circ} \mathrm{C}\end{array}$ & Gsolsimia & Klorida & - \\
\hline 10 & & Ciarinem & $\begin{array}{l}42,0^{\circ} \mathrm{C}- \\
52,0^{\circ} \mathrm{C}\end{array}$ & Geologi & $120,0^{\circ} \mathrm{C}$ & Geolsimia & Asam sulfat & - \\
\hline 11 & Subang & Sagalaherang & $\begin{array}{l}30,0^{\circ} \mathrm{C}- \\
58,0^{\circ} \mathrm{C}\end{array}$ & Geologi & - & - & $\begin{array}{c}\text { Bikarbonat- } \\
\text { Norida }\end{array}$ & - \\
\hline 12 & \multirow{4}{*}{ Tasitsmalaya } & Ciheuras & - & - & $\begin{array}{l}103,0^{\circ} \mathrm{C}- \\
197,0^{\circ} \mathrm{C}\end{array}$ & Geolsinia & $\begin{array}{c}\text { Klorida- } \\
\text { sulfat }\end{array}$ & - \\
\hline 13 & & Cigunung & $\begin{array}{l}34,0^{\circ} \mathrm{C}- \\
57,0^{\circ} \mathrm{C}\end{array}$ & Geolimia & - & - & $\begin{array}{c}\text { Kiorida- } \\
\text { bikarbonat }\end{array}$ & $6,1-7,0$ \\
\hline 14 & & Cibalong & $\begin{array}{c}50,5,0^{\circ} \mathrm{C}- \\
54,0^{\circ} \mathrm{C}\end{array}$ & Geolsimia & - & - & - & 6,1 \\
\hline 15 & & $\begin{array}{c}\text { Gumung } \\
\text { Calsabuana }\end{array}$ & - & - & $\begin{array}{l}100,0^{\circ} \mathrm{C}- \\
200,0^{\circ} \mathrm{C}\end{array}$ & Geclogi & - & - \\
\hline 16 & Cirebon & $\begin{array}{l}\text { Gunung } \\
\text { Kromong }\end{array}$ & - & - & $210,0^{\circ} \mathrm{C}$ & Geolsimia & $\begin{array}{c}\text { Kiorida, } \\
\text { Bitarbonat, } \\
\text { danSulfat }\end{array}$ & - \\
\hline 17 & \multirow[t]{2}{*}{ Kuningen } & Subang & $60,0^{\circ} \mathrm{C}$ & Geologi & $90,0^{\circ} \mathrm{C}$ & Geolsimia & Kloride & $6,0-7,0$ \\
\hline 18 & & Cibingbin & - & - & - & - & - & 7,68 \\
\hline
\end{tabular}

Tabel 3. Data statistik sumber energi geotermal wujud brine dan kondensat di Jawa Barat [9]

\begin{tabular}{|c|c|c|c|c|c|c|}
\hline \multirow{3}{*}{ No } & \multicolumn{6}{|c|}{ TIIIK POTENSI PANAS BUMI JAWA BARAT (WILAYAH PEMBANGKIT LISTRIK) } \\
\hline & \multirow{2}{*}{$\begin{array}{l}\text { Wilayah } \\
\text { Geotermal }\end{array}$} & \multirow{2}{*}{ Jenis $P$ anas Terbuang } & \multicolumn{4}{|c|}{ STUDI MANIFESTASI KONDENSAT DANBRINE } \\
\hline & & & Temperatur & Tekanan & Laju Aliran & Beban Panas \\
\hline 1 & Kamojang & Kondensat & $46,0^{\circ} \mathrm{C}$ & Q,1 bar & $100 \mathrm{~kg} / \mathrm{s}$ & $19,18 \mathrm{MW}$ \\
\hline 2 & \multirow{3}{*}{ Wayang Winds } & Brine & $1560^{\circ} \mathrm{C}$ & 5,6 bar & $50 \mathrm{~kg} / \mathrm{s}$ & $32,94 \mathrm{MW}$ \\
\hline 3 & & Kondensat 1 & $49,0^{\circ} \mathrm{C}$ & 5,3 bar & $26 \mathrm{~kg} / \mathrm{s}$ & $5,38 \mathrm{MWV}$ \\
\hline 4 & & Kondensat 2 & $49,0^{\circ} \mathrm{C}$ & 0,9 bar & $60 \mathrm{~kg} / \mathrm{s}$ & $12,41 \mathrm{MW}$ \\
\hline 5 & Patha & Brine & $165,0^{\circ} \mathrm{C}$ & 7,0 bar & $27,78 \mathrm{~kg} / \mathrm{s}$ & $19,36 \mathrm{MW}$ \\
\hline 6 & \multirow{2}{*}{ GunungSalak } & Brine & $173,0^{\circ} \mathrm{C}$ & $6,6 \mathrm{bar}$ & $252 \mathrm{~kg} / \mathrm{s}$ & $184,97 \mathrm{MW}$ \\
\hline 7 & & Kondensat & $46,0^{\circ} \mathrm{C}$ & 0,1 bar & $\mathrm{N} / \mathrm{A}$ & $18,43 \mathrm{MWV}$ \\
\hline 8 & Darajat & Kondensat & $46,0^{\circ} \mathrm{C}$ & 0,1 bar & $135 \mathrm{~kg} / \mathrm{s}$ & $25,89 \mathrm{MWV}$ \\
\hline
\end{tabular}




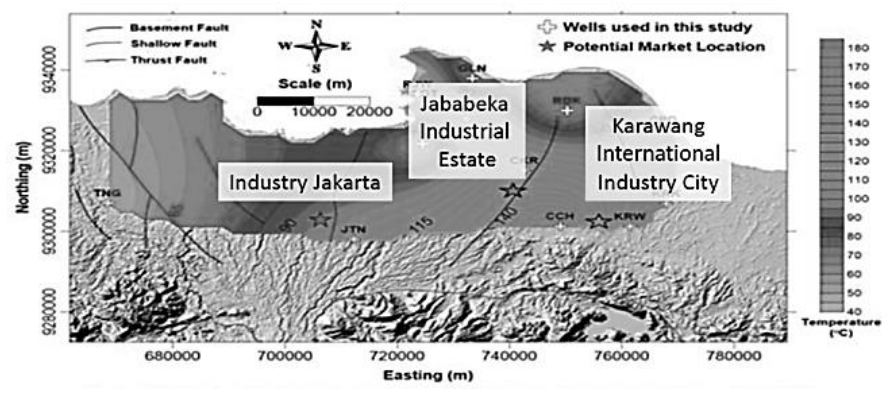

Gambar 3. Lokasi panas terbuang dari sedimentary basin [6]

\subsection{Potensi Mata Pencaharian sebagai Heat User di Jawa Barat}

\subsubsection{Sektor Pertanian}

Salah satu sektor yang memiliki potensi besar dalam pengembangan penggunaan panas bumi di Jawa Barat adalah sektor pertanian. Hal ini ditunjukan dengan keikutsertaan Jawa Barat sebagai produsen pangan nasional, sebagai contoh produsen beras nasional sebesar 17,76\%. Akan tetapi, setiap tahun dari tahun 2003 hingga 2013, berdasarkan data statistik, berbagai subsektor mengalami penurunan pada segi jumlah usaha rumah tangga atau usaha pribadi masyarakat (lihat Gambar 5). Hal ini dapat disebabkan berbagai macam faktor, salah satu diantaranya adalah biaya produksi yang tinggi.

Dalam usaha menekan perekonomian agar terus berkembang dari segi biaya produksi, beberapa subsektor yang merupakan pengguna panas (heat user) seperti hortikultura, akuakultur (perikanan), dan jasa-jasa pengolahan hasil pertanian (pengeringan hasil panen, penadahan hasil panen, dan lain-lain) dapat ditekan dengan penggunaan sumber energi panas bumi entalpi rendah yang masih belum dapat dimanfaatkan secara maksimum di wilayah usaha sebagai wilayah terbuka.

a

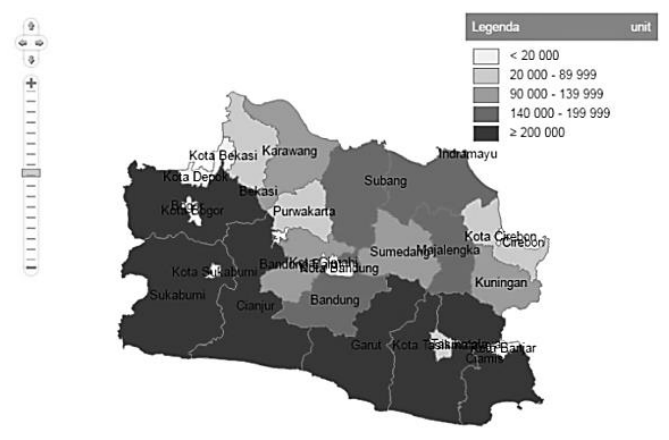

b

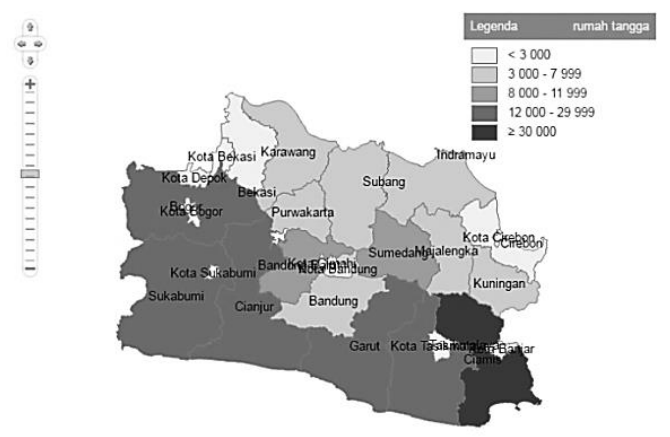

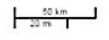
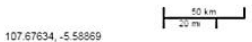

Gambar 4. Peta penyebaran a).Unit usaha pertanian b). Rumah tangga usaha pengolahan hasil pertanian tahun 2013 di Jawa Barat [9]

Hal ini didukung dengan data statistik BPS Indonesia mengenai penyebaran usaha pertanian skala rumah tangga di wilayah Jawa Barat (lihat Gambar 4). Konsentrasi terbesar dengan jumlah usaha di atas 200.000 unit berada pada wilayah kota / 
kabupaten Cianjur, Bogor, Sukabumi, Garut, Tasikmalaya, dan Ciamis. Sedangkan berdasarkan data penyebaran jasa pengolahan pertanian, konsentrasi terbesar dengan jumlah usaha di atas 30.000 usaha berada pada wilayah kota / kabupaten Ciamis dan Banjar [8].

\subsubsection{Subsektor Hortikultura}

Subsektor hortikultura merupakan sub-bagian pertanian yang membudidayakan tanaman seperti sayuran, buah-buahan, dan tanaman hias. Pada daerah Jawa Barat produksi tanaman hortikultura berdasarkan potensi dari hasil pencacahan sensus pertanian tahun 2013 diperoleh jumlah usaha rumah tangga total sebesar 1.255.717 rumah tangga. Ruta usaha ini menurun dibandingkan tahun 2003 sebanyak 947.951 rumah tangga atau sebesar $-43,02 \%$ [8].

\section{GRAFIK RUMAH TANGGA USAHA SEKTOR PERTANIAN 2003 DAN 2013}

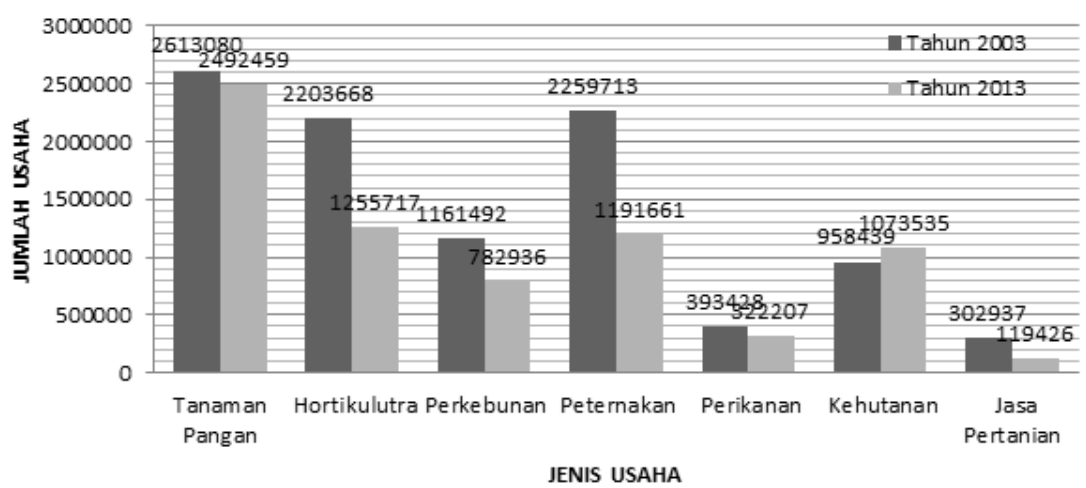

Gambar 5. Grafik distribusi usaha rumah tangga pada sektor pertanian tahun 2003 dan 2013 di Jawa Barat [8]

Faktor utama keberhasilan budidaya tanaman ini, umumnya adalah pada pengontrolan temperatur ruang penanaman. Dengan kemajuan teknologi, sumber panas ruangan dapat berasal dari energi panas bumi sebagai alternatif energi energi fosil. Fasilitas pemanfaatan panas bumi secara langsung ditunjukan dengan skema berikut ini (lihat Gambar 6).

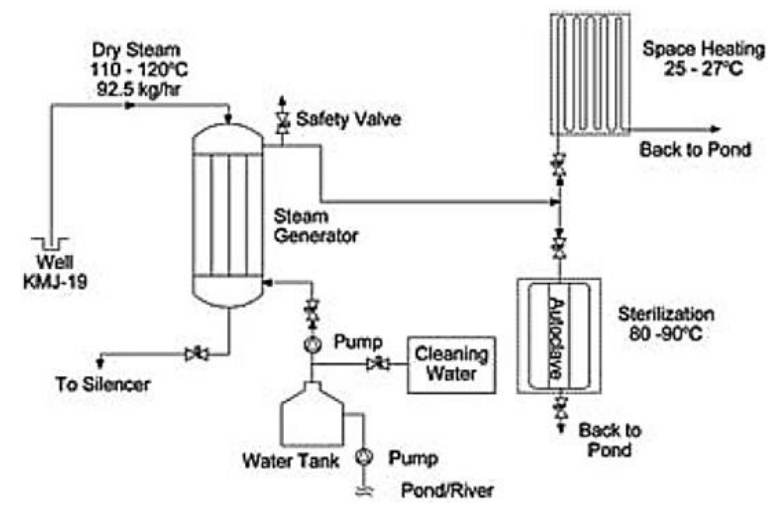

Gambar 6. Skema diagram budidaya jamur dengan pemanfaatan uap panas bumi [6]

Salah satu pemanfaatan skema energi panas bumi tersebut berada di Kamojang, Jawa Barat yang digunakan sebagai sarana penanaman jamur. Fasilitas panas 
bekerja dimulai pada uap kering yang muncul pada sumur berkapasitas kecil dengan temperatur $110-120^{\circ} \mathrm{C}$ yang diarahkan secara langsung menuju steam generator sebagai pemanas air. Uap yang terpanaskan digunakan untuk mensterilisasikan media penanaman jamur atau yang disebut dengan "bag-log" dan juga digunakan sebagai pemanas ruangan untuk menjaga kamar inkubasi tetap hangat (lihat Gambar 7). Penggunaan uap digunakan sebagai pengganti bahan bakar fosil (kerosin) yang semakin lama semakin mahal. Dengan mengadopsi fasilitas ini, berdasarkan data Provinsi Jawa Barat sejak tahun 2006, kapasitas penyediaan bag-log dapat mencapai 25.000 kantong setiap bulan dan dapat dijual pada masyarakat lokal dengan harga murah [6].

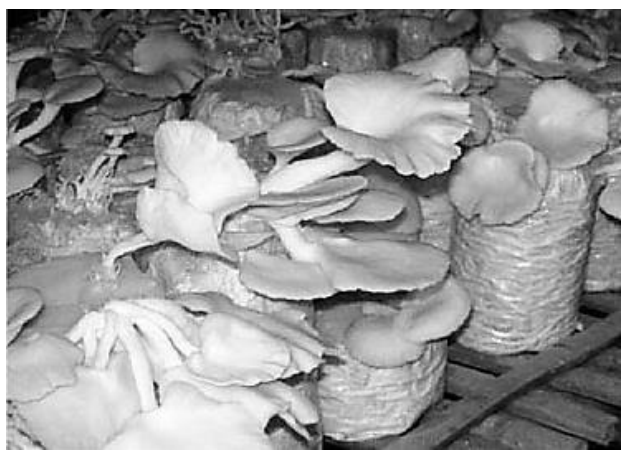

Gambar 7. Budidaya jamur dari sumber energi geotermal direct use di Kamojang [6]

\subsubsection{Subsektor Akuakultur atau Perikanan}

Menurut Surana (2010), pada saat ini di Indonesia fasilitas yang memanfaatkan fluida geotermal sebagai akuakultur atau ternak ikan hanya berada di provinsi Lampung. Metode yang digunakan adalah menggabungkan air panas geotermal dengan air sungai sebagai media pertumbuhan ikan lele [6].

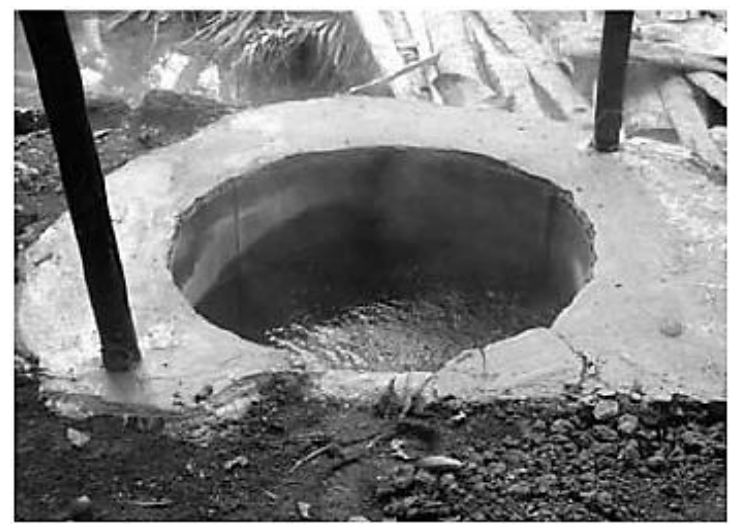

Gambar 8. Sumur geotermal buatan pada daerah resapan sesudah pengembangan [6]

\subsubsection{Subsektor Jasa Pertanian}

Di sisi lain sektor pertanian, pengolahan hasil panen didukung oleh jasa pertanian. Potensi dalam hal ini akan linier dengan berkembangannya pertanian di Jawa Barat, yang besar. Meskipun kapasitas jasa tersedia masih minim. Hal ini terlihat pada grafik usaha tahun 2013 berjumlah 1.075.935 rumah tangga yang masih jauh di bawah jumlah beberapa usaha subsektor pertanian lainnya. Pada grafik pun terlihat bahwa usaha jasa pertanian dari tahun 2003 hingga 2015 mengalami penurunan. Hal ini dapat disebabkan oleh salah satu faktornya adalah minim 
teknologi dengan biaya yang rendah, seperti halnya energi termal berentalpi rendah, yang umumnya terbuang dengan percuma [6].

Salah satu jasa pertanian yang umum dilakukan adalah pengeringan hasil panen, seperti pengeringan Kopra dan Kokoa di Way Ratai, Lampung. Pengeringan dilakukan dengan memanfaatkan sumur dangkal alami geotermal dan sumur dangkal geotermal artifisial secara bergantian [6]. Lapangan geotermal Way Ratai ini belum dikembangkan secara khusus yang berlokasi di area penanaman kelapa dengan banyak sumur bertemperatur $80^{\circ} \mathrm{C}-98^{\circ} \mathrm{C}$ berkapasitas $200 \mathrm{~kg}$ setiap batch dengan skema pada Gambar 9.

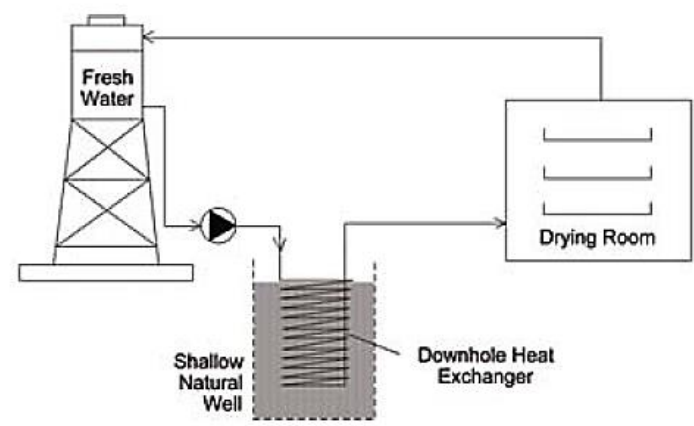

Gambar 9. Skema pengeringan kopra dengan memanfaatkan sumur dangkal geotermal alami [6]

Pemanfaatan skema tersebut diawali dengan fasilitas heat exchanger di dalam sumur geotermal alami sedalam 2 meter yang dialiri air ke dalamnya. Air yang terpanaskan kemudian diarahkan menuju ruang pengeringan dengan temperatur $50^{\circ} \mathrm{C}$ berprinsipkan panas konduktif. Berdasarkan BPPT, hasil pengeringan kopra dan kokoa yang dihasilkan memiliki hasil yang lebih baik dibandingkan cara konvensional. Hal ini dikarenakan tidak adanya asap yang mengontaminasi [6].

\subsubsection{Sektor Pariwisata}

Secara luas pemanfaatan langsung sumber energi geotermal dengan entalpi rendah adalah sebagai pemandian air panas dan kolam renang. Berdasarkan data BPPT, pemanfaatan energi geotermal dalam aplikasi ini, tidaklah diketahui banyak jumlahnya. Akan tetapi, berdasarkan Pertamina Geothermal Energy, pemanfaatan energi geotermal di aplikasi ini sudahlah berlangsung selama 10 tahun (lihat Gambar 10) [6].

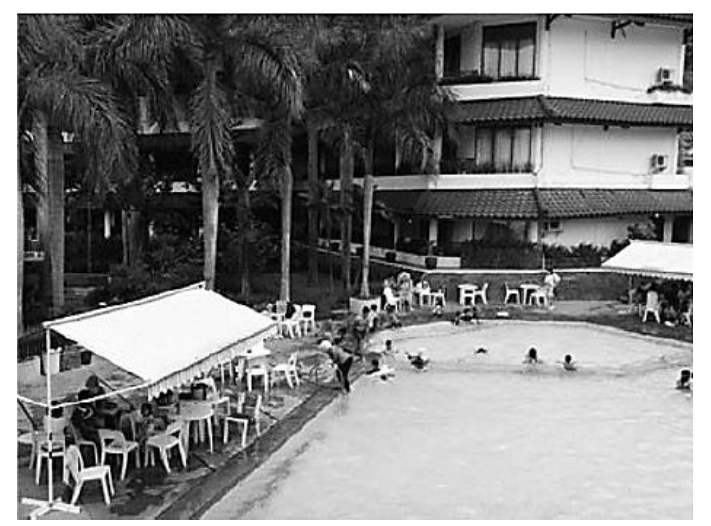

Gambar 10. Kolam renang air panas di Cipanas [6] 


\subsection{Hasil Pemetaan Pemanfaatan Potensi Energi Termal Entalpi Rendah di Jawa Barat}

Berdasarkan hasil observasi energi geotermal entalpi rendah dan mata pencaharian lokal pada Tabel 2 dan Gambar 4, dihasilkan peta pemanfaatan di Jawa Barat seperti terlihat pada Gambar 11.

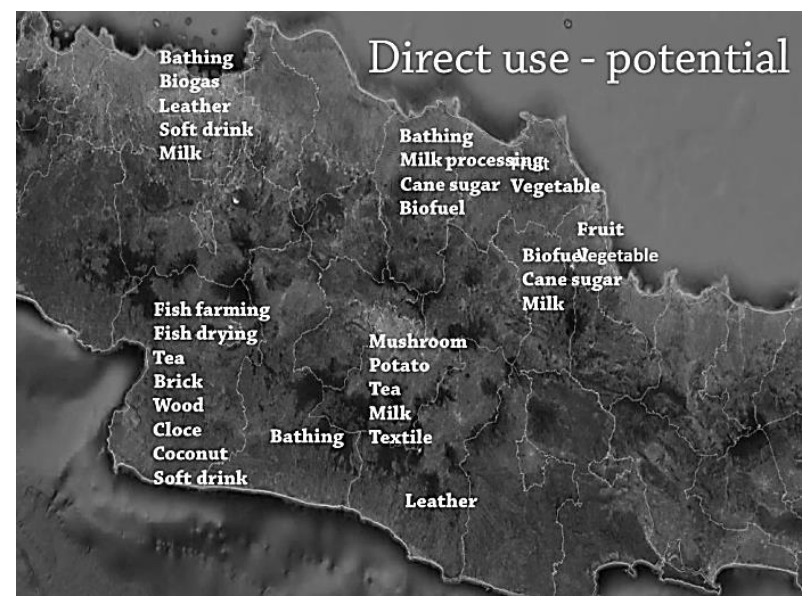

Gambar 11. Hasil pemetaan pemanfaatan energi geotermal direct-use

\section{Pemodelan dan Peran Kerja Komponen}

\subsection{Kriteria Pemanfaatan}

Dasar dari pemanfaatan sumber enrgi geotermal agar dapat difungsikan secara maksimal oleh berbagai mata pencaharian lokal adalah hal utama yang perlu diketahui sebelum berlanjut pada sebuah pengembangan yang besar. Kriteria pemanfaatan sumber energi geotermal direct-use antara lain :

- Jarak dari sumber ke lokasi kurang dari $20 \mathrm{~km}$;

- Temperatur maksimum yang dibutuhkan harus lebih rendah dari temperatur permukaan geothermal dari sumber panas;

- Kebutuhan panas harus lebih rendah dari beban yang bisa diberikan oleh sumber;

\subsection{Pemodelan dan Peranan Kerja}

\subsubsection{Observasi Potensi Geotermal, Mata Pencaharian, dan Industri}

Pada tahapan observasi literatur dilakukan pengumpulan data statistik setiap potensi geotermal, mata pencaharian lokal, dan industri yang kemudian dipetakan dan dicocokan menjadi satu kesatuan guna memenuhi syarat screening pengembangan model pemanfaatan. Pengumpulan data dilakukan atas kerjasama pihak perguruan tinggi dan lembaga penelitian dengan kerja sama penerangan informasi data yang berasal dari pemerintahan, baik pusat maupun daerah.

\subsubsection{Pre-Processing}

Pada tahapan pre-processing dilakukan persiapan pemanfaatan sumber energi geotermal secara nyata untuk didistribusikan pada unit usaha lokal, baik berupa pemilihan sumber geotermal yang tepat berdasarakan kebutuhan panas beban yang tepat dan modeling untuk pembangunan jalur pipa sebagai media distribusi. 
Pada proses ini menyangkut peranan perguruan tinggi selaku perancang proses persiapan dan pembangunan yang disertai implementasi lapangan oleh pemerintah.

\subsubsection{Mekanisme Pemanfaatan}

Pada tahapan proses mekanisme pemanfaatan dilakukan pekerjaan yang terbagi oleh dasar 3 peranan, yaitu yang dilakukan oleh perguruan tinggi-lembaga penelitian, pemerintahan, dan masyarakat. Berbagai analisis, seperti kinerja peralatan prototipe, wilayah kerja, dan finansial dilakukan oleh perguruan tinggi dan lembaga penelitian. Sedangkan kemampuan SDM dan keikutsertaan pihak terkait diseleksi oleh pemerintahan, selaku pemegang kekuasan setempat, terhadap berbagai lini masyarakat yang berpotensi, tanpa luput dari saran pihak perguruan tinggi dan lembaga penelitian.

\subsubsection{Produk}

Pada proses produksi dilakukan analisis produk, diantaranya ketersedian input untuk waktu mendatang, kontrol kualitas berdasarkan survei pada konsumen, dan packaging sebagai wajah produk terakhir sebagai sisi estetika di pasaran. Hal ini dilakukan atas peran masyarakat sebagai pemegang usaha unit kecil, pebisnis sebagai pemegang usaha unit besar dan berbadan hukum (terutama terbentuknya suatu badan usaha milik negara (BUMN)), disertai oleh pemerintah sebagai penguji kualitas produk (BPOM, dan lain-lain), dan CSR sebagai landasan tanggung jawab kompensasi atas muculnya suatu dinamika teknologi baru, baik bagi lingkungan dan masyarakat lokal sekitar.

\subsubsection{Konsumen}

Pada bagian konsumen, masyarakat berperan sebagai pengelola unit usaha kecil. Sedangkan pebisnis berperan sebagai pengelola unit usaha besar. Keduanya menjalankan strategi marketing guna mencapai hasil ekonomis yang menguntungkan bagi seluruh lini pengembang, baik sebelum masuk ke dalam pasar lokal maupun internasional. Proses ini kemudian akan berakhir pada tangan konsumen yang di antaranya adalah masyarakat luas atau berbagai macam unit industri yang membutuhkan.

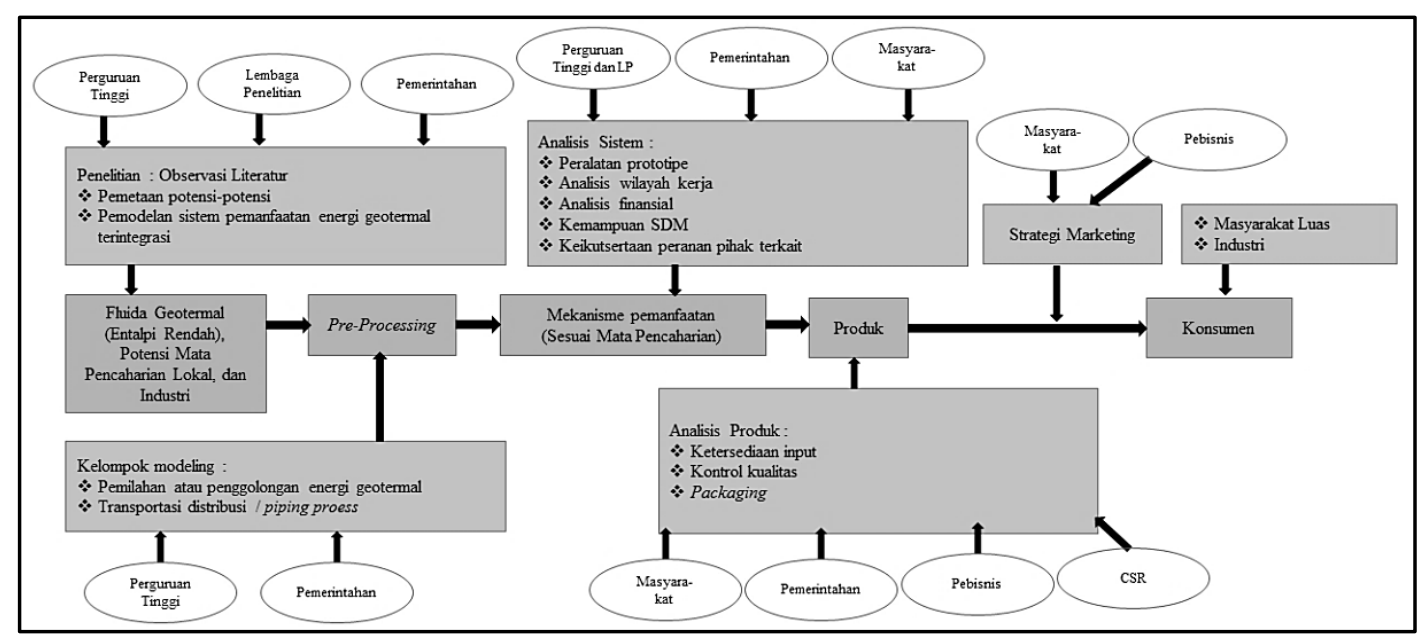

Gambar 12. Diagram model pendayagunaan energi geotermal dan sistem pemanfaatannya 


\section{Kesimpulan}

Telah berhasil dibuat peta pemanfaatan energi geoteramal dengan entalpi rendah di Jawa Barat. Secara garis besar terkonsentrasi di Kota Cirebon, Kuningan, Subang, Bogor, Garut, Kab. Bandung, Sukabumi, dan Cianjur, yang dimanfaatkan untuk pemandian, biogas, pengeringan hasil panen, pengeringan ikan, soft drink, kulit, tekstil, dan lain-lain.

Telah berhasil pula dibuat model pendayagunaan energi geotermal entalpi rendah yang melibatkan komponen akdemisi (perguruan tinggi dan lembaga penelitian), masyarakat, pemerintah daerah, pemerintah pusat, dan pihak swasta serta negeri sebagai pemiliki modal (pebisnis). Setiap pihak memiliki peran masing-masing yang terintegrasi pada kerangka aktivitas utama.

\section{Daftar Pustaka}

1. DOE National Laboratory. 2004. Geothermal Technologies Program : Direct Use. Washington : U.S Department of Energy.

2. Ayling BF, Budd AR, Holgate FL, and Gerner E. 2007b. Direct-Use of Geothermal Energy :Opportunities for Australia. Geoscience Australia Fact Sheet, GEOCAT \#65454.

3. Johannesson, T. and Chatenay, C. Direct Use of Geothermal Resources. Presented at "Short Course VI on Utilization of Low-and Medium Enthalpy Geothermal Resources and Financial Aspects of Utilization", orginized by UNU-GTP and LaGeo, in Santa Tecla, El Salvador, March 23-29, 2014.

4. Lindal, B. 1973. Geothermal Energy :Industrial and Other Applications of Geothermal Energy. Paris : UNESCO.

5. Lund, J. W., Freeston, D. H., Boyd, T. L. 2011. Direct Utilization of Geothermal Energy 2010 Worldwide Review. Geothermics 40, pp. 159-180.

6. Surana, T., Atmojo, J. P., Suyanto, Subandriya, A. 2010. Development of Geothermal Energy Direct Use in Indonesia. GHC BULLETIN, pp.11-15.

7. Tim Penyusun. 2012. Profil Potensi Panas Bumi Indonesia. Jakarta : Kementrian ESDM.

8. Tim Penyusun. 2013. Sensus Pertanian 2013 (Jawa Barat). [Online] Tersedia : http://st2013.bps.go.id. (Diakses pada 29 September 2016 pada pukul 13.03).

9. Tim Penyusun. 2016. Market Survey : Potential Direct Use of Geothermal waste Heat in West Java. Presentation for GEOCAP Workshop at ITB. 